\title{
Soluble matrix from osteoblastic cells induces mineralization by dental pulp cells
}

\author{
Akemichi Ueno', Kikuji Yamashita², Keiko Miyoshi', Taigo Horiguchi', Intan Ruspita1, \\ Kaori $\mathrm{Abe}^{1}$, and Takafumi Noma ${ }^{1}$ \\ ${ }^{1}$ Department of Molecular Biology, and ${ }^{2}$ Department of Oral and Maxillofacial Anatomy, Institute \\ of Health Biosciences, The University of Tokushima Graduate School, Tokushima, Japan
}

\begin{abstract}
Dental pulp cells have a capacity to differentiate into mineralization-inducing cells. To clarify the molecular mechanism, we established an in vitro mineralization-inducing system by rat clonal dental pulp cell line, RPC-C2A, and tried to purify a mineralizationinducing factor in conditioned medium (CM) from preosteoblastic MC3T3-E1 cells. The active factor was impermeable to an ultrafiltrating membrane, and sedimented by ultracentrifugation. The sedimented factor was found as a needle-like structure about $1.3 \mu \mathrm{m}$ in average length as observed by transmission electron microscopy. The factor contained type I collagen, suggesting not a matrix vesicle, but a soluble matrix. The mineralizationinducing activity was also detected in CM from primary culture of rat calvaria (RC) cells. These results suggested that the soluble matrices from osteoblastic cells serve, at least in part, as differentiation-inducing agents. J. Med. Invest. 53 : 297-302, August, 2006
\end{abstract}

Keywords : dental pulp cells ; osteoblast ; extracellular matrix ; mineralization

\section{INTRODUCTION}

Although both dental pulp and dentin originate from mesenchymal dental papilla, the former remains unmineralized while the latter is highly mineralized (1). Dental pulp cells are responsible for homeostasis of dental mineralized tissue. For example, pulp tissue forms reparative dentin in protective response to external stimuli including caries, chemicals, and trauma $(2,3)$. In addition, the size of the dental pulp cavity is reduced as a result of peritubular dentin deposition with advancing age (4). On the other hand, the incidence of pulp stone formation that is also a mineralized product is not age-dependent (5). The regulatory mechanisms of

Abbreviations: BMP, bone morphogenetic protein ; $\mathrm{CBB}$, Coomassie brilliant blue ; CM, conditioned medium ; MW, molecular weight ; RC, rat calvaria ; RT-PCR, reverse transcriptionPCR; SDS-PAGE, sodium dodecyl sulfate-polyacrylamide gel electrophoresis ; TEM, transmission electron microscopy ; TGF- $\beta$, transforming growth factor-beta; WCE, whole cell extract both mineralization-inducing activity and maintaining activity in the unmineralized state remain to be clarified.

Matrix mineralization is observed in primary culture of pulp cells. In contrast, clonal pulp cells do not easily produce mineralized nodules even though osteogenic agents such as bone morphogenetic proteins (BMPs) are added to the culture as shown previously (6). On the other hand, mouse calvaria-derived preosteoblastic cell line MC3T3E1 not only forms mineralized nodules steadily (7) but also secretes a variety of cytokines including BMP-2 and BMP-4 $(8,9)$. No other established cell line induces matrix mineralization easily. In addition, conditioned medium (CM) from MC3T3-

Received for publication May 17, 2006; accepted June 16, 2006.

Address correspondence and reprint requests to Takafumi Noma, Department of Molecular Biology, Institute of Health Biosciences, The University of Tokushima Graduate School, Kuramoto-cho, Tokushima 770-8504, Japan and Fax: +81-88633-7326. 
E1 cells induce mineralization by clonal rat dental pulp cells, whereas $\mathrm{CM}$ from rat osteosarcoma cells ROS $17 / 2.8$, normal human articular chondrocytes, or normal human dermal fibroblasts do not induce mineralization by them in vitro ((6), and unpublished observation by Ueno et al.). There are several diverse mechanisms of mineral deposition during the formation of hard tissues. Acellular mineralization in biodegradable three-dimensional structures occurs in cell-free culture media (10) as well as at the implantation sites (11) and in the early stage of cementum formation in molars (12). On the other hand, it is generally accepted that cellular mineralization is initiated by release of matrix vesicles from living cells and by apoptotic bodies from dying cells $(13,14)$. It is well known that matrix vesicles contain actin, annexins II and $\mathrm{V}$, carbonic anhydrase, phosphatases (pyrophosphatase, alkaline phosphatase (ALP), 5'AMPase, Ca-ATPase), proteoglycan link protein, type $\mathrm{X}$ collagen, calbindin, lactate dehydrogenase, membrane-derived phospholipids, but not type I collagen $(13,14)$. In contrast, the constituents of media vesicles and soluble matrix remain unknown. However, vesicle-mediated mineralization is not observed in many invertebrates and enamel tissues $(15,16)$. Thus the mechanism of initiation of matrix mineral deposition still remains to be determined.

In this study to investigate both mineralizationinducing and maintaining mechanisms at a molecular level, we partially purified and characterized the active substance from CM of preosteoblastic MC3T3-E1 cells, applying von Kossa staining as well as performing the transmission electron microscopic analysis.

\section{MATERIALS AND METHODS}

\section{RT-PCR analysis}

Total RNA was isolated with TRI REAGENT (Molecular Research Center) from RDP4-1, RPC-C2A, AtT20, Balb3T3, and C3H10T1/2 cells, reverse transcribed with oligo(dT), and subjected to PCR within the log-linear range of amplification for either ALP, BMP-2, BMP-4 (30 cycles), or GAPDH (20 cycles). ALP , BMP-2, BMP-4, and GAPDHspecific primers were as follows : ALP forward, 5'-CTGGACCTCATCAGGATTTG-3' ; ALP reverse, 5'- GCTGTGAAGGGCTTCTTGTC - 3'; BMP-2 forward, 5'TGAACACAGCTGGTCTCAGG - 3'; BMP-2 reverse, 5'- GCTAAGCTCAGTGGGGACAC - 3'; BMP-4 forward,
5'- CAGAGCCAACACTGTGAGG - 3'; BMP-4 reverse, 5'-TCCACTCCCTTGAGGTAACG - 3'; GAPDH forward, 5'- CATTGACCTCAACTACATGG - 3'; GAPDH reverse, 5'CTCAGTGTAGCCCAGGATGC-3'.

\section{Cell culture}

Confluent RPC-C2A cells and RDP 4-1 cells were cultured for 10 days in $\alpha-M E M$ medium supplemented with $0.22 \% \mathrm{NaHCO}_{3}$, antibiotics, $10 \% \mathrm{FBS}$, $2 \mathrm{mM} \beta$-glycerophsphate, $50 \mu \mathrm{g} / \mathrm{ml} \mathrm{L}$-ascorbic acid, and $10^{-8} \mathrm{M}$ dexamethasone with or without $50 \% \mathrm{CM}$ as described previously (6). The cells were subjected to phase-contrast microscopy in a Nikon TM-D microscope (Nikon).

Transmission electron micrographs of sedimented active matrices

Culture fluid from day 1 to 4 after confluency was centrifuged to remove cells and cell debris for $5 \mathrm{~min}$ at $800 \mathrm{xg}$ and $\mathrm{CM}$ was collected from the supernatant. After the $\mathrm{CM}$ was centrifuged for $30 \mathrm{~min}$ at $10,000 \mathrm{xg}$, the supernatant was subjected to ultracentrifugation for $3 \mathrm{~h}$ at $150,000 \mathrm{xg}$ in a Beckman TLA 100.3 rotor. For transmission electron microscopy, the fixed and ethanol-dehydrated pellets were embedded in Epon 812 (TAAB Laboratories) and sections were cut on an LKB Ultratome V (LKB). Ultrathin sections were double-stained with uranyl acetate in $50 \%$ ethanol and Reynolds solution and examined in a Hitachi H-800 electron microscope (Hitachi).

\section{Western blot analysis}

Samples $(40 \mu \mathrm{g})$ were separated by $7.5 \%$ SDSpolyacrylamide gel electrophoresis as described previously (17). Proteins were transferred electrophoretically to polyvinylidene difluoride (PVDF) membranes (Immobilon-P ; Millipore). The membranes were blocked with TBS-T buffer $(20 \mathrm{mM}$ Tris-HCl, $137 \mathrm{mM} \mathrm{NaCl}, 0.1 \%$ Tween-20, pH 7.5) containing 5\% skim milk (Difco) and labeled with rabbit anti-mouse type I collagen antibody (Calbiochem) (1:500 diluted) and then with horseradish peroxidase-conjugated donkey anti-rabbit IgG (Amersham Biosciences). Immunoreactive bands were located using an ECL Western blotting detection kit (Amersham Biosciences) and RX-U Xray film (Fujifilm). The relative intensity of the signals measured by JOYCE-LOEBL Microdensitometer 3CS (Joyce-Loebl).

Mineralization-inducing assay 
Confluent RPC-C2A cells were cultured for 10 days with or without $\mathrm{CM}$ from either RC cells or MC3T3-E1 cells. For staining of mineralized nodules, the cells were fixed with $10 \%$ neutral buffered formalin and stained by the von Kossa technique with $3 \%$ silver nitrate as described previously (18).

\section{Cell growth}

CM from RC cells or MC3T3-E1 cells was added to the culture of confluent RPC-C2A cells. Cell growth was measured with the metabolic indicator Alamar Blue (Biosource International) (10\% of incubation volume), which was added at $24 \mathrm{~h}$ after $\mathrm{CM}$ treatment (19). After a 4-hour incubation, part of the medium was collected and the extent of proliferation was determined by measuring each plate at $570 \mathrm{~nm}$ and $600 \mathrm{~nm}$ for each plate in a Beckman DU 8 spectrophotometer. To obtain the specific absorbance for the level of the reduced state, the absorbance at $600 \mathrm{~nm}$ was subtracted from that at $570 \mathrm{~nm}$. The cell-free blank value was then subtracted from each value. Data obtained from the mean of two separate experiments in triplicate are expressed as percentage of control $(0 \% \mathrm{CM})$.

\section{RESULTS}

\section{Expressions of osteogenic related genes}

Extracellular matrix (ECM) mineralization is a physiological process in bones and teeth while a pathological process in anywhere else. Although the molecular mechanisms for ECM mineralization are not fully understood, ALPs such as tissuenonspecific alkaline phosphatase and BMPs are possibly involved in the formation of mineralized matrix made up of hydroxyapatite and type I collagen (20). At first, RT-PCR analysis was performed to examine the expressions of osteogenic related genes including BMP2, BMP4, and alkaline phosphatase, in clonal cell lines without exogenous factors (Fig. 1A). BMP-2mRNA was detected in RDP4-1, another clonal rat dental pulp-derived cell line, and C3H10T1/2 cells which also differentiate to osteoblastic cells. The only cell line that simultaneously expressed three osteogenic mRNA (BMP-2, BMP-4, and alkaline phosphatase) was RPC-C 2 A, suggesting that this may be is the best target dental pulp-derived cell line for the induction of mineralization among clonal cell lines examined.
Addition of CM from MC3T3-E1 cells has a significant effect upon bone nodule formation by RPCC2A cells, but not by RDP4-1 cells (Fig. 1B). The active factor(s) in CM was not filtered through an ultrafiltration membrane (MW cutoff : 1,000,000), suggesting a large complex. Thus, $\mathrm{CM}$ was subjected to ultracentrifugation at $150,000 \mathrm{xg}$ for $3 \mathrm{~h}$ after centrifugation at $10,000 \mathrm{xg}$ for $30 \mathrm{~min}$. Mineralizationinducing activity was sedimented as approximately 1.3- $\mu \mathrm{m}$-long needle-like complexes as revealed by TEM (Fig. 2). These sedimentable matrices exhib-

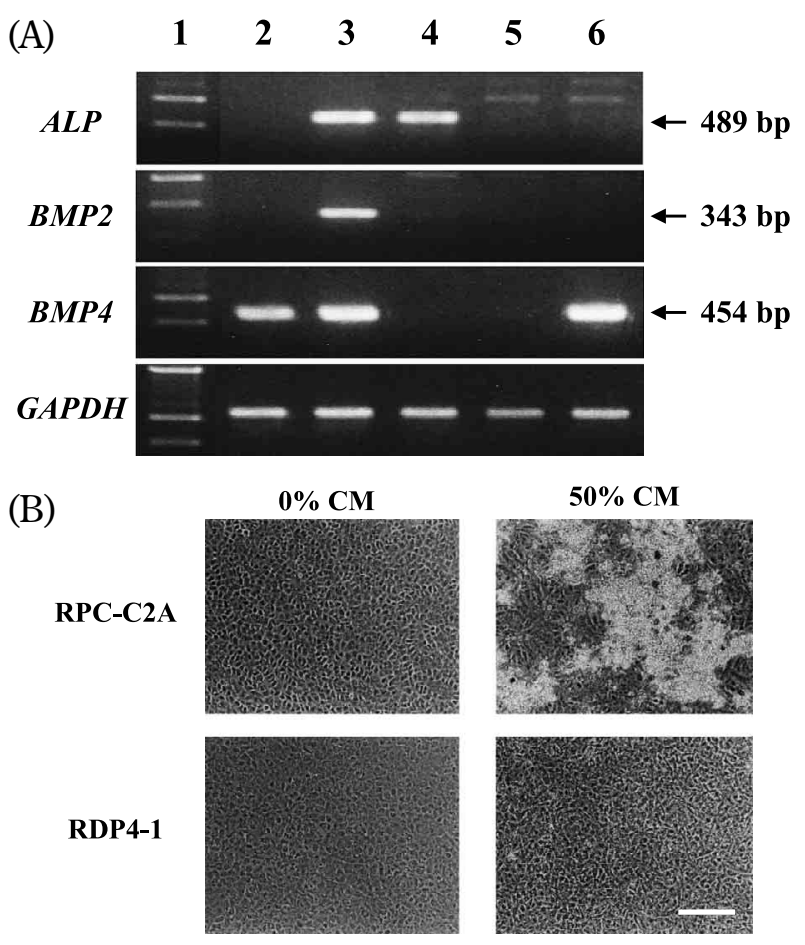

Fig. 1 RPC-C2A cells express osteogenic genes and produce bone nodules after treatment with conditioned medium from MC 3T3-E1 cells. (A) RT-PCR analysis of $A L P, B M P-2, B M P-4$, and GAPDH mRNA. Lane 1, size marker; lane 2, RDP-4-1 cells; lane 3 , RPC-C2A cells ; lane 4, AtT 20 cells, mouse pituitary tumor-derived cell line; lane $5, \mathrm{Balb} / \mathrm{c} 3 \mathrm{~T} 3$ cells ; lane $6, \mathrm{C} 3 \mathrm{H}$ $10 \mathrm{~T} 1 / 2$ cells. (B) Phase-contrast micrograph of rat dental pulp cells treated with conditioned medium (CM) from MC3T3-E1 cells. Bar, $200 \mu \mathrm{m}$.
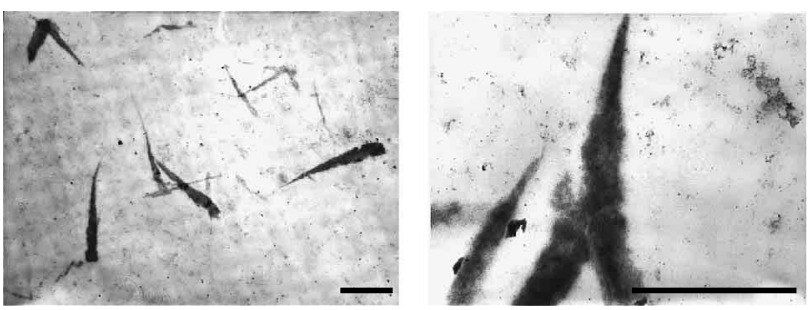

Fig. 2 Transmission electron micrographs of sedimented active matrices. After ultracentrifugation of $\mathrm{CM}$, the fixed and ethanol-dehydrated pellets were embedded in Epon 812 and sections were prepared with an LKB Ultratome V. Ultra thin sections were examined in a Hitachi $\mathrm{H}-800$ electron microscope. Bar, $1 \mu \mathrm{m}$. 
ited mineralization-inducing activity in RPC-C2A cells. The mineralizing-inducing activity exclusively resided in the sedimented matrices not in the supernatant. In addition, we found that collagenase treatment lost both structure and activity of sedimented matrices (data not shown).

\section{Western blot analysis}

In general, matrix vesicles do not contain type I collagen $(13,14)$. The CBB-stained SDS-PAGE pattern of sedimented matrices showed that the sample was not easily dissociated with a reducing agent and that the molecular weight seemed too high to run into a separation gel, suggesting that the sedimented matrices contain collagens. In order to verify whether the complex was a matrix vesicle or soluble matrix, SDS-PAGE and immunoblot analyses with anti-type I collagen antibody were performed. CBB-stained gel showed that most of the large MW sample did not move into the separation gel, suggesting that it did not dissociate easily with the SDS sample buffer (21) once after sedimented (Fig. 3A). After immunoblotting, type I collagen molecules containing $\alpha 1$ and $\alpha 2$ chains were detected at about $2: 1$ ratio in the dissociated sample in addition to the undenatured large MW collagen (lane 2 in Fig. 3B). In whole cell extract (WCE), the possible degradation products were also observed (lane 1 in Fig. 3B). These results suggest that the factor secreted is not a matrix vesicle but a soluble matrix.
(A)

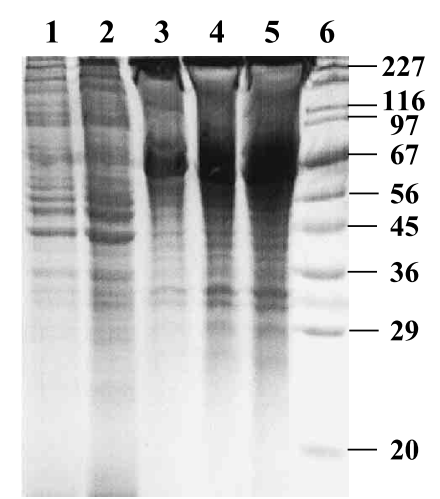

(B)

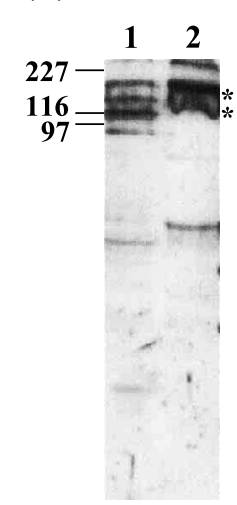

Fig. 3 Detection of type I collagen in the sedimented matrix. (A) Samples were separated by $7.5 \%$ SDS-polyacrylamide gel electrophoresis and the gel was stained with Coomassie bril-

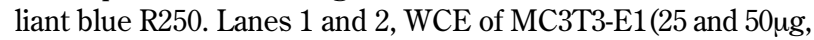
respectively) ; lanes $3-5,150,000 \mathrm{xg}$ pellet $(25,50$, and $75 \mu \mathrm{g}$, respectively) ; lane 6 , broad-range molecular weight (MW) marker (Apro Science). MWs (x10-3) are shown at the right margin. (B) Western blot analysis was performed with rabbit antimouse type I collagen antibody and horseradish peroxidaseconjugated donkey anti-rabbit IgG. Lane 1, MC3T3-E1 WCE; lane 2,150,000xg pellet. Star $\left(^{*}\right)$ indicates immunoreactive bands.

\section{von Kossa staining}

Next, in order to determine if a matrix such as this is restricted and specific to MC3T3-E1 cells, $\mathrm{CM}$ from primary-cultured rat calvaria $(\mathrm{RC})$ cells (22) was examined for the activity of matrix mineralization of RPC-C2A cells. The multilayered RPCC2A cells and the mineralized nodules stained strongly by von Kossa technique (18) in their ECM were observed (Fig 4A).

\section{Alamar Blue assay}

ince the cell proliferation-promoting activity with $\mathrm{CM}$ from RC cells was observed by phase-contrast microscopy, Alamar Blue assay was performed to quantify the reduction ability by mitochondria (18) (Fig. 4B). CM from RC cells exhibited stimulation of the RPC-C2A cell growth by 1.8-fold, whereas $\mathrm{CM}$ from MC3T3-E1 cells was without effect, indicating that the RC CM includes a growth factor in addition to a differentiation factor.

\section{(A)}

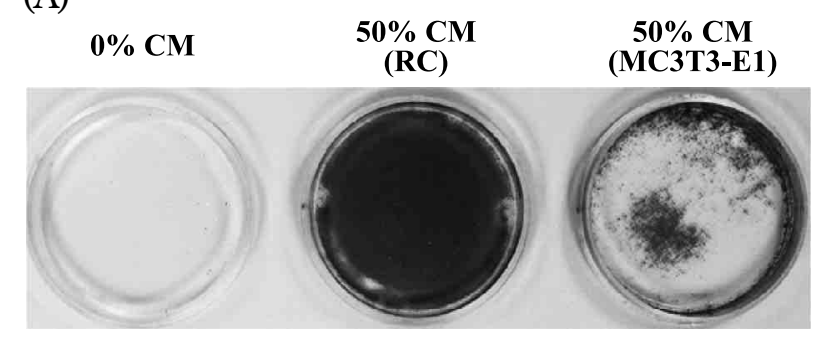

(B)

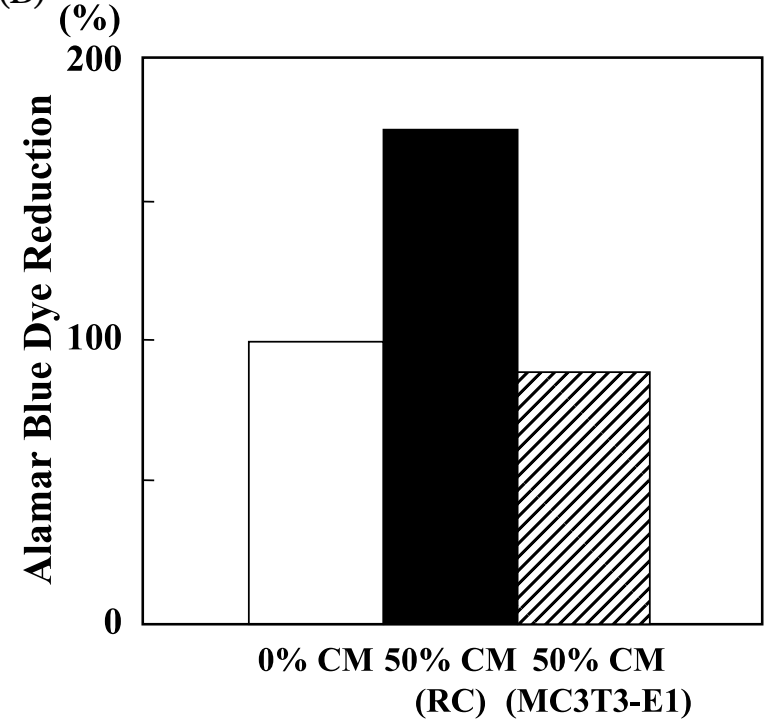

Fig. 4 Effect of $\mathrm{CM}$ from primary-cultured rat calvaria (RC) cells on mineralization and proliferation of RPC-C2A cells. (A) Confluent RPC-C2A cells were cultured with or without CM from either RC cells or MC3T3-E1 cells. In order to detect mineralized nodules, the cells were stained by the von Kossa technique. (B) CM from RC cells or MC3T3-E1 cells was added to the culture of confluent RPC-C2A cells. Cell growth was evaluated with Alamar Blue assay. 


\section{DISCUSSION}

In the present study, the mineralization-inducing factor was found to be sedimented by ultracentrifugation and composed of at least type I collagen (Figs. 2 and 3B). The matrix vesicle does not contain type I collagen and shows a round shape with approximately $200 \mathrm{~nm}$ in diameter at maximum $(13,14)$. Therefore, this mineralization-inducing factor is thought to be a kind of soluble matrix that possibly contains a differentiation factor and other ECM molecules besides type I collagen. To further examine both the potency and generality of induction of matrix mineralization by $\mathrm{CM}$ from osteoblastic cells, we analyzed for $\mathrm{CM}$ from $\mathrm{RC}$ cells (Fig. 4A). The CM from RC cells has an extremely strong effect on matrix mineralization of RPC-C2A cells with the maximal concentration at $50 \%$ in medium, demonstrating a stronger activity than that of CM from MC3T3-E1 cells. This may be because MC3T3-E1 cells lost the capacity to produce a certain growth factor and a differentiation factor during the course of subculture by a number of generations (7). A growth factor increases the number of precursor cells differentiating to osteoblasts, resulting in enhanced matrix mineralization.

In conclusion, we found that not only MC3T3-E1 cells but also RC cells produce the sedimentable matrices containing at least type I collagen (Fig. 2) that have an ECM mineralization inducing activity. The both structure and activity of sedimented matrices were lost by collagenase treatment, suggesting the importance and an involvement of type I in mineralization inducing activity. It is well known that extracellular matrix vesicles are not always the site of initial mineral deposition (13-16). In certain cell culture systems (23) and in turkey tendon (24), matrix vesicle and collagen mineralization start simultaneously but distinct in site. In addition, there are no extracellular matrix vesicles in many invertebrates and in enamel $(15,16)$. Therefore, there must be other means of initiating mineralization besides accumulating ions in a protected environment as matrix vesicles do. For example, as one of the new paradigms for the morphogenesis of calcium-based biominerals, Olszta et al proposed the mineralization of type I collagen via a polymer-induced amorphous liquid-precursor process $(25,26)$. We believe that the results obtained from the present study provide another important issues for the new basic mechanism of inducing matrix mineralization other than wellestablished matrix vesicles. Further molecular characterization and identification of the mineralization inducing activity in the $\mathrm{CM}$ is required to apply for medical purpose in future, including therapy for osteoporosis.

\section{REFERENCES}

1. Linde A:The extracellular matrix of the dental pulp and dentin. J Dent Res 64 : 523-529, 1985

2. Yamamura T:Differentiation of pulpal cells and inductive influence of various matrices with reference to pulpal wound healing. J Dent Res 64 : 530-540, 1985

3. Tziafas D : Basic mechanisms of cytodifferentiation and dentinogenesis during dental pulp Repair. Int J Dev Biol 39 : 281-290, 1995

4. Kvaal SI, Koppang HS, Solheim T: Relationship between age and deposit of peritubular dentine. Gerodontology 11 : 93-98, 1994

5. Al-Hadi Hamasha A, Darwazeh A : Prevalence of pulp stones in Jordanian adults. Oral Surg Oral Med Oral Pathol Oral Radiol Endod 86 : 730-732, 1998

6. Ueno A, Kitase $\mathrm{Y}$, Moriyama K, Inoue H : MC3T3-E1-conditioned medium-induced mineralization by clonal rat dental pulp cells. Matrix Biol 20 : 347-355. 2001

7. Sudo H, Kodama HA, Amagai Y, Yamamoto S, Kasai S: In vitro differentiation and calcification in a new clonal osteogenic cell line derived from newborn mouse calvaria, J Cell Biol 96 : 191-198, 1983

8. Amarnani S, Merriman HL, Linkhart TA, Baylink DJ, Mohan S: Autocrine regulators of MC3T3-E1 cell proliferation. J Bone Miner Res $8: 157-165,1993$

9. Suzawa M, Takeuchi Y, Fukumoto S, Kato S, Ueno N, Miyazono K, Matsumoto T, Fujita T: Extracellular matrix-associated bone morphogenetic proteins are essential for differentiation of murine osteoblastic cells in vitro. Endocrinology $140: 2125-2133,1999$

10. Andre-Frei V, Chevallay B, Orly I, Boudeulle M, Huc A, Herbage D : Acellular mineral deposition in collagen-based biomaterials incubated in cell culture media. Calcif Tissue Int 66:204211, 2000

11. Yamashita $\mathrm{K}$, Takagi $\mathrm{T}$ : Calcification preceding new bone formation induced by demineral- 
ized bone matrix gelatin. Arch Histol Cytol $55: 1-43,1992$

12. Yamamoto T, Domon T, Takahashi S, Arambawatta AK, Wakita M : Immunolocation of proteoglycans and bone-related noncollagenous glycoproteins in developing acellular cementum of rat molars. Cell Tissue Res 317: 299-312, 2004

13. Anderson HC : Molecular biology of matrix vesicles. Clin Orthop 314 : 266-280, 1995

14. Anderson HC: Matrix vesicles and calcification. Curr Rheumatol Rep 5 : 222-226, 2003

15. Boskey $\mathrm{AL}:$ Matrix proteins and mineralization: an overview. Connect Tissue Res 35 : 357-363, 1996.

16. Hohling HJ, Arnold S, Barckhaus RH, Plate U, Wiesmann HP : Structural relationship between the primary crystal formations and the matrix macromolecules in different hard tissues. Discussion of a general principle. Connect Tissue Res 33 : 171-178, 1995

17. Islam MR, Ueno A, Nishikawa $H$, Nagata $T$, Inoue $\mathrm{H}$ : Osteotropic factor-stimulated synthesis of thrombospondin in rat dental pulp cells. FEBS Lett 393 : 193-196, 1996

18. Otsuka E, Yamaguchi A, Hirose S, Hagiwara H: Characterization of osteoblastic differentiation of stromal cell line ST2 that is induced by ascorbic acid. Am J Physiol 277 : C132-C138, 1999

19. Ahmed SA, Gogal RM, Walsh Jr JE : A new rapid and simple non-radioactive assay to monitor and determine the proliferation of lymphocytes: an alternative to $\left[{ }^{3} \mathrm{H}\right]$ thymidine incorporation assay. J Immunol Methods 170 : 211-224, 1994

20. Murshed M, Harmey D, Millan JL, McKee MD, Karsenty G : Unique coexpression in osteoblasts of broadly expressed genes accounts for the spatial restriction of ECM mineralization to bone. Genes Dev 19 : 1093-1104, 2005

21. Laemmli UK: Cleavage of structural proteins during the assembly of the head of bacteriophage T4. Nature 227 : 680-685, 1970

22. Bellows CG, Aubin J E, Heersche JN : Physiological concentrations of glucocorticoids stimulate formation of bone nodules from isolated rat calvaria cells in vitro. Endocrinology 121 : 1985-1992, 1987

23. Boskey AL, Stiner D, Leboy P, Doty S, Bindernan I: Optimal conditions for cartilage calcification in differentiating chick limb-bud mesenchymal cells. Bone and Mineral 14 : 11-37, 1992

24. Landis WJ : Temporal sequence of mineralization in calcifying turkey tendon. In : WT Butler, eds. The Chemistry and Biology of Mineralized Tissues. Ebsco Media., Birmingham, 1985, pp. 360-364

25. Olszta MJ, Douglas EP, Gower LB : Scanning electron microscopic analysis of the mineralization of type I collagen via a polymer-induced liquid-precursor (PILP) process. Calcif Tissue Int $72: 583-591,2003$

26. Olszta MJ, Odom DJ, Douglas EP, Gower LB: A new paradigm for biomineral formation: mineralization via an amorphous liquid-phase precursor. Connect Tissue Res 44 (Suppl 1) : 326-334, 2003 